\title{
Impact of COVID-19 on fossil energies and its consequence in climate change, and nine other environmental indicators
}

\author{
A. Rashedi a,b, ${ }^{*}$, Taslima Khanam a , R. Saidur ${ }^{c, d}$ \\ ${ }^{a}$ College of Engineering, IT \& Environment, Charles Darwin University, Ellengowan Drive, \\ Casuarina, Northern Territory 0810, Australia \\ ${ }^{b}$ Faculty of Business, Economics \& Law, The University of Queensland, St Lucia Queensland \\ 4067, Australia \\ 'Research Center for Nano-Materials and Energy Technology (RCNMET), School of Science \\ and Technology, Sunway University, Bandar Sunway, Petaling Jaya, 47500, Selangor Darul \\ Ehsan, Malaysia \\ ${ }^{d}$ Department of Engineering, Lancaster University, Lancaster, LA1 4YW, UK \\ ${ }^{*}$ Correspondence to: mabrur.rashedi@cdu.edu.au (A. Rashedi).
}

\begin{abstract}
COVID-19 pandemic, also known as the coronavirus pandemic, has spread rapidly across the globe since the end of $\mathbf{2 0 1 9}$ and brought impressive changes in our life and living through partial or full lockdown and reduced anthropogenic activities. Hence, it is imperative to investigate the impacts and consequences of COVID-19 on global ecosystem and environment. The present study accordingly addresses the impacts and consequences of COVID-19 by ten environmental indicators; viz., global warming (or greenhouse gas emission), stratospheric ozone depletion, ozone formation (on human health), fine particulate matter formation, smog, ionizing radiation, human carcinogenic toxicity, human non-carcinogenic toxicity, water resource consumption, and effect on human health. The overall study has been performed in agreement with the standard principle and guidelines of life cycle assessment. Worldwide changes in consumption of fossil fuels, viz., petroleum, coal and natural gas, as a result of COVID-19 pandemic, has
\end{abstract} been the core theme of the study. Outcomes from the study show that COVID-19 has been 
a 'blessing in disguise' for the global environment with most of the above-mentioned indicators declining by approximately 20-30\% in 2020 in comparison to the 2019 level.

\section{Keywords}

COVID-19, fossil fuels, life cycle assessment (LCA), climate change, environment, impact

\section{Introduction}

The Novel Coronavirus disease 2019 (COVID-19) has spread rapidly across the globe since Dec, 2019, ushering in a sweeping upheaval to human society and global economy ${ }^{1,2}$. In a matter of weeks, the pillars of modern civilization have essentially ground to a halt. Airplanes, restaurants and playgrounds suddenly became empty; businesses deemed nonessential; bustling streets were deserted and city after city fell silent as desperate governments enforced residents to stay indoor in order to stymie the spread of the disease. These changes, however, appeared as a boon to the global environment. Researchers from different parts of the world have confirmed that the air ${ }^{1-3}$ and water ${ }^{4-6}$ quality have significantly improved and the emission of particulate matters and other pollutants have sharply declined in many countries since the outbreak. Such rapid changes in the environment were unheard of in the past decades and have remarkably been occurring at a time when the world has simultaneously been grappling with different environmental issues; viz., climate change $e^{7-11}$, air pollution ${ }^{1-3,10}$, water pollution ${ }^{4,5,10,11}$, acidification ${ }^{7,11}$, eutrophication $7,8,10,11$, toxicity ${ }^{10,11}$, hazardous waste ${ }^{10,11}$, radioactive waste ${ }^{7,8,10,11}$, ozone layer depletion $6-8,10,11$, etc. Given the ensemble of the aforementioned issues, it is expected that the COVID-19 situation and consequent reduction in anthropogenic activities will 
deliver a significant improvement and/or reversal in global environmental trends. Therefore, the authors deem the following questions worthy of exploration in this unique time:

i) how COVID-19 situation and consequential drop in anthropogenic activities unveil changes to the global environment; and,

ii) specially, how COVID-19 situation affects the global greenhouse gas (GHG) emission with respect to the recent baseline studies by the Intergovernmental Panel on Climate Change (IPCC).

In order to answer these questions, the authors identify life cycle assessment (LCA) as the most promising methodological tool due to its capability to conduct the whole life cycle based analysis of all input-output flows starting from extraction of resources from nature to all interim life cycle phases to until the final end-of-life phase ${ }^{8,10,11}$. However, finding the comprehensive and real-time datasets of all anthropogenic activities that have or have not been slowed, halted or ceased due to COVID-19 situation is challenging as these represent an enormous data set and, even in an ideal situation, these involve tremendously large number of assumptions, simplifications and uncertainties ${ }^{2,5,11}$. The authors, therefore, rely on major linchpins of modern civilizations, viz., oil, gas and coal based fossil energies; nearreal time consumption data of which are available on monthly basis in various public domains $^{12-14}$. More importantly, the fossil based energies shape almost every sector of modern life, living and society whether it is food production, clothing, accommodation, health, transportation, or any other industrial process or service. The current civilization is, therefore, befittingly called the 'age of oil'15,16. This study, accordingly, evaluates the changes in global environment based on sudden change in global consumption of fossil fuels owing to COVID-19 situation. 
Details of the changes in global consumption of fossil fuels have been discussed in various reports. Out of these, the present article sources the data from: i) Monthly Energy Review Apr 2020 report DOE/EIA-0035(2020/4) ${ }^{12}$, ii) Short-Term Energy Outlook Jun 2020 report $^{13}$, iii) Short-Term Energy Outlook Aug 2020 report $^{14}$. All these reports have been published by Energy Information Administration (EIA), the leading statistical and research wing of the Department of Energy, USA, and one of the most prominent organizations of its kind in the world. Out of these, EIA Short-Term Energy Outlook Aug 2020 report discusses on the impact of COVID-19 on fossil fuel consumption, as such: "Reduced economic activity related to the COVID-19 pandemic has caused changes in energy demand and supply patterns in 2020. Uncertainties persist across the U.S. Energy Information Administration's (EIA) outlook for all energy sources, including liquid fuels, natural gas, electricity, coal, and renewables"14. In another instance, the report states on the consumption of petroleum products that "The decline reflects travel restrictions and reduced economic activity related to COVID-19 mitigation efforts"14. In a similar vein, EIA Short-Term Energy Outlook Jun 2020 report states that "U.S. liquefied natural gas exports will decline through the end of the summer as a result of reduced global demand for natural gas"13. Moreover, EIA forecasts that coal production will decrease by $26 \%$ in 2020 due to reduced demand from global steel production, coking coal and steam coal ${ }^{13,14}$ and the consumption will again rise by $20 \%$ in 2021 in case there is a smooth recovery from COVID-19 pandemic ${ }^{14}$. Therefore, change in consumption of fossil fuels and contemporary change in environmental impacts stand as a major issue to deliberate on in this hour.

Overall, the present study accompanies at least two novelties in corresponding domains of knowledge, such as: 
i) this is the first LCA based study that unravels the effects of COVID-19 on global environment. Accordingly, the study evaluates the changes in global environment by 10 LCA impact categories: a) global warming, b) stratospheric ozone depletion, c) ozone formation (human health), d) fine particulate matter formation, e) smog, f) ionizing radiation, g) human carcinogenic toxicity, h) human non-carcinogenic toxicity, i) water consumption, and, j) effect on human health - changes in none of these environmental impacts owing to COVID-19 situation has been studied so far from the LCA perspective; and,

ii) this is the first study that highlights how much change each major fossil fuel carries to the global environment in 2020 by aforesaid 10 LCA impact indicators.

These novelties have been affirmed based on systematic literature search studies conducted in three prominent research databases; such as, Scopus, ScienceDirect and Web of Science, latest in Sep, 2020. Some of the search criteria include: i) TITLE-ABS-KEY ( ( covid OR coronavirus ) AND ( "life cycle assessment" OR "life cycle analysis" ) ); ii) TITLE-ABS-KEY ( ( covid OR coronavirus ) AND ( "climate change" OR "global warming" OR carbon )) which resulted in total 661 documents in Scopus database but none of these focuses on the LCA of fossil resources and their associated impacts on global environment as a result of COVID-19 pandemic situation.

\section{Methodology}

The LCA study has been performed following the guidelines of relevant international standards, as envisaged in ISO 14040 and ISO $14044^{17,18}$. Accordingly, the LCA study combines four major steps, as follows: i) goal and scope definition of the LCA study, ii) 
defining, arranging the life cycle inventory, iii) performing life cycle impact assessment (LCIA), and iv) interpretation of LCA results. Out of these four, the first three steps are described sequentially in this section while the last step is the focus of the "Results and discussion" section.

\subsection{Goal and scope definition}

The change in the consumption of widely used fossil fuels as a result of the COVID-19 pandemic situation forms the basis of the study. Consumption of three major fossil fuels, such as, petroleum, natural gas and coal, has been studied in this context. As a cradle to grave study, it models the entire life cycle processes of fossil fuels, including extraction from nature to entire production, refining, transportation, distribution to operational phase in different industry sectors to end-of-life emissions, as displayed in Figure 1. Out of the fossil fuels, consumption of petroleum based products except crude oil includes their production in field, production in renewable fuels and oxygenate plants, production in refineries and blenders, imports, net receipts, adjustments in inventory, minus exports, minus refinery and blender net inputs, minus stock change $\mathrm{e}^{12,13}$.

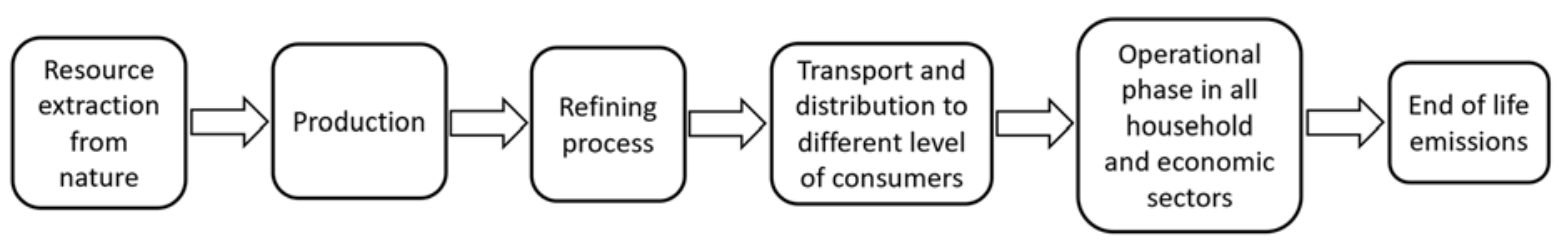

Figure 1: Life cycle processes of the fossil fuels

Likewise, for natural gas, the consumption data include the following: i) use in commercial sector together with use in commercial combined-heat-and power (CHP) and commercial 
electricity-only plant, ii) use in industrial sector (lease and plant fuel use, industrial CHP, industrial electricity-only plants, consumption for non-combustion use and other industrial deliveries), iii) use in transportation sector (pipelines and distribution use, and vehicle fuel use), iv) use in electric power sector (electric utility and independent power producer use) and, v) use in residential sector ${ }^{12,13}$. Consecutively, the consumption of coal has been based on the data from: i) coke plants, ii) electric power, iii) residential, iv) commercial, and, v) industrial sector ${ }^{12-14}$. The EIA reports classify the petroleum and other liquids in seven subcategories - these include: hydrocarbon gas liquid, unfinished oil, motor gasoline, jet fuel, distillate fuel oil, residual fuel oil, and other oils. Details of the seven liquids and their components have been discussed in aforesaid EIA reports ${ }^{12,13}$. Consumption data of all major fossil fuels in the world in the year 2019 and 2020 have been highlighted in Table 1. Details of the methodology have been presented in Supplementary Materials (S1-S3). Additionally, relevant consumption data of fossil fuels have been highlighted in Supplementary Tables 1-6.

\subsection{Life cycle inventory and life cycle assessment process}

Each of the fossil fuels has been modelled either by defining new LCl process or using equivalent $\mathrm{LCl}$ process out of the existing $\mathrm{LCl}$ databases ${ }^{19-21}$. Details of these $\mathrm{LCl}$ processes have been presented in Supplementary Material S3. Additionally, three state-of-the-art LCA methods have been used in the study, such as: i) ReCiPe 2016 mid-point $(H)$ method version 1.03, ii) Recipe 2016 end-point $(H)$ version 1.03, and, iii) TRACl 2.1 version 1.05. Out of these, ReCiPe 2016 is one of the most robust LCA methods worldwide which has been developed in collaboration between Dutch National Institute for Public Health and the Environment (RIVM), Radboud University Nijmegen, Norwegian University of Science and 
Technology, and PRé Consultants ${ }^{22}$. This method combines the strengths of both mid-pointbased LCA approach of CML-IA, and end-point-based LCA approach of Eco-indicator 99 methods. In addition, the Tool for Reduction and Assessment of Chemicals and Other Environmental Impacts or briefly "TRACI" is another well-renowned method which is widely used in industrial ecology, environment and sustainability studies and has been developed by US Environmental Protection Agency ${ }^{23}$. The present study is based on the latest updates of these LCA methods.

Table 1: Global fossil fuel consumption in 2019 and 2020

\begin{tabular}{cccc}
\hline Fuel type & Unit & Consumption in & Consumption in \\
& & 2019 & 2020 \\
Hydrocarbon gas & billion litre per year & 895.43 & 880.42 \\
liquid & & & \\
Unfinished oil & billion litre per year & 14.30 & 10.44 \\
Motor gasoline & billion litre per year & 2652.67 & 2413.15 \\
Jet fuel & billion litre per year & 497.78 & 359.33 \\
Distillate fuel oil & billion litre per year & 1167.92 & 1092.14 \\
Residual fuel oil & billion litre per year & 77.96 & 72.31 \\
Other oils & billion litre per year & 547.13 & 555.39 \\
Natural gas & billion m $^{3}$ per year & 3829.41 & 3698.11 \\
Coal & billion kg per year & 7796.42 & 5224.16 \\
\hline
\end{tabular}


Out of the three, ReCiPe mid-point and TRACI methods provide mid-point impact based results while ReCiPe end-point provides end-point or damage oriented results. The midpoint impact results are calculated directly based on the life cycle processes, wastes and emissions of a system or technology while each end-point oriented impact is generally an aggregated form of a few mid-point based impacts and outlines the impact of a system or technology by ultimate 'areas of protection' or damage categories ${ }^{22,24}$. On a methodological note, the authors hereby explore only the characterized results of both mid-point and endpoint impact indicators and, therefore, no normalization or weighting data set has been specified in the study. In addition, hierarchist LCA methodology has been applied in ReCiPe methods to determine the LCA impacts on moderate or medium term perspective rather than opting for individualist or egalitarian perspective that focuses on short or very long term results, respectively ${ }^{7,22}$

Accordingly, the mid-point impact 'smog' has been calculated by TRACI method while 'effect on human health', an end-point impact, has been quantified by ReCiPe end-point method. Rest of the eight mid-point based impacts have been calculated by ReCiPe mid-point method. Overall LCA modelling has been conducted in licensed SimaPro LCA software platform version 9.0.0.4124.

\section{Results and discussion}

The Results and discussion covers three sections where Section 3.1 highlights the results of mid-point impact indicators; Section 3.2 focuses on the results of end-point impact indicator and Section 3.3 highlights total GHG emission worldwide in 2020 incorporating the GHG contribution by fossil fuels, as found in Section 3.1, together with the remaining GHG 
contribution by non-fossil sources without considering any change in this sub-compartment because of COVID-19 situation.

\subsection{Results of mid-point based environmental impacts}

\subsubsection{Global warming}

Global warming impact has been calculated based on the global warming potential (GWP) of total 207 GHGs, for a time horizon of 100 years, as suggested in the IPCC 5th Assessment reports (AR5) ${ }^{25,26}$. Emission of these GHGs increases the radiative forcing capacity in the atmosphere which in turn increases the global mean surface temperature; thereby leading to global warming and climate change phenomena. The results of global warming and other eight mid-point impacts have been illustrated in Figure 2. It is evident from the figure that coal is the predominant source of global warming within all fossil fuels in both 2019 and 2020 followed by natural gas, hydrocarbon gas liquid, motor gasoline and distillate fuel oil. Out of the three major types of coal, anthracite carries the highest global warming impact, followed by bituminous and lignite coal, respectively. About $2.44 \mathrm{~kg}$ carbon dioxide equivalent $\left(\mathrm{kg} \mathrm{CO}_{2}\right.$ eq) methane is emitted to the environment based on various life cycle processes of $1 \mathrm{~kg}$ lignite coal. This increases to about 2.98 and $3.57 \mathrm{~kg} \mathrm{CO}$ eq GHGs for bituminous and anthracite coals, respectively. Due to COVID-19 situation, worldwide consumption of coal will reduce by $\sim 32.99 \%$ which will shrink the global warming impact by coal by 7.71 billion metric ton $\mathrm{CO}_{2}$ eq in 2020 (see Table 1). As like coal, global warming impact by natural gas will reduce by $\sim 3.43 \%$ in 2020 . In a quantitative scale, 1 cubic meter $\left(\mathrm{m}^{3}\right)$ natural gas carries much lower global warming impact of $\sim 0.621 \mathrm{~kg} \mathrm{CO} 2$ eq. Out of this, emissions of methane, carbon dioxide and dinitrogen monoxide stand at approximately (approx.) $0.419,0.2$ and $0.00117 \mathrm{~kg} \mathrm{CO}_{2}$ eq, respectively. Other than coal and natural gas, 
use of all types of petroleum and other liquids will diminish in 2020 except 'other oils'. In total, reduced use of gasoline, jet fuel, distillate fuel oil and hydrocarbon gas liquid will slash the global warming impact by approx. 104, 46.3, 36.8 and 26.5 million metric ton $\mathrm{CO}_{2}$ eq, respectively, in 2020 . Consumption of hydrocarbon gas liquid only shrinks by $\sim 1.68 \%$ in 2020 with respect to its base consumption level in 2019; this results in a lower decline of its GHG emission in comparison to other fossil fuels under study. By contrast, use of 'other oils' will increase by $\sim 1.51 \%$ in 2020 which will intensify the global warming impact by $\sim 3.72$ million metric ton $\mathrm{CO}_{2}$ eq. In turn, changes in global warming impact by jet fuel will not be significant although global aviation industry has been experiencing a major shift in COVID-19 situation. This can be attributed to two factors - i) jet fuel is consumed in a very low quantity in comparison to other fuels - 497 billion litre (i.e., $~ 8.5 \%$ of total worldwide petroleum consumption) in 2019 versus 359 billion litre (i.e., $6.67 \%$ of total worldwide petroleum consumption) in 2020; and ii) per kg global warming potential of jet fuel is $\sim 1.67 \mathrm{E}+11 \mathrm{~kg} \mathrm{CO} 2$ eq which is much lower in comparison to all other fossil fuels except residual fuel oil and unfinished oil.

\subsubsection{Stratospheric ozone depletion}

As like global warming, a time horizon of 100 years has been considered for 21 ozone depleting substances (ODS) to quantify the stratospheric ozone depletion impact based on the recent guidelines of World Meteorological Organization ${ }^{27,28}$. Emissions of ODSs such as chlorine or bromine based chemicals ultimately increase their concentration in troposphere and stratosphere which in turn interact with the stratospheric ozone layer and decrease the concentration of ozone - this finally results in large scale ultraviolet radiations hitting the earth $^{22}$. Out of the fossil fuels, coal, natural gas, jet fuel and hydrocarbon gas liquid deliver 
significant stratospheric ozone depletion impact and, accordingly, these are the leading fossil fuels that ensure major reduction in stratospheric ozone depletion in 2020 due to COVID-19 situation. Out of these three, the life cycle processes of per kg coal carry $\sim 1.4 \mathrm{E}-6$ kg CFC-11 eq ozone depletion impact where CFC stands for chlorofluorocarbon. By comparison, the life cycle processes of per kg hydrocarbon gas liquid and per $\mathrm{m}^{3}$ natural gas carry about 5.87E-7 and 3.53E-7 CFC-11 eq ozone depletion impact, respectively. In total, diminished use of coal, natural gas, jet fuel and hydrocarbon gas liquid will slash the ozone depletion impact by approx. 3.6E+06, 4.63E+04, 8.94E+03, 8.81E+03 kg CFC-11 globally in 2020. Contrarily, due to $\sim 1.51 \%$ increase in consumption, 'other oils' will raise the same impact by $\sim 1.96 \mathrm{E}+03 \mathrm{~kg}$ CFC-11 globally in the same time.

\subsubsection{Ozone formation (human health)}

As like the above-mentioned ones, there will be drastic reduction in environmental impact by ozone formation (human health) impact category in 2020 due to COVID-19 situation. Although no ozone is directly emitted to the atmosphere due to the life cycle processes of the fossil fuels under study, it is formed as a result of photochemical reaction of nitrogen oxides $\left(\mathrm{NO}_{\mathrm{x}}\right)$ and non-methane volatile organic compounds (NMVOCs) and it carries intense potential to be a health hazard through infecting lungs, airways and respiratory systems; thereby causing significant respiratory issues to human being ${ }^{22,29}$. Ozone formation additionally inhibits the growth of seeds, crops and vegetables and decreases the productivity of plant species thus carrying consequential long term damages to the terrestrial ecosystems. On a quantitative scale, the life cycle processes of per litre hydrocarbon gas liquid carry $0.0232 \mathrm{~kg} \mathrm{NO}_{\mathrm{x}}$ eq ozone formation (human health) impact which is the highest value among all petroleum products and liquids followed by motor 
gasoline with $\sim 0.0028 \mathrm{~kg} \mathrm{NO}$ eq impact for per litre based life cycle processes. Coal, on the other hand, carries $0.0074 \mathrm{~kg} \mathrm{NO}$ x eq ozone impact for per $\mathrm{kg}$ life cycle processes. Consumption of coal, jet fuel and unfinished oil reduces by approx. $32.99 \%, 27.81 \%$ and $27.04 \%$, respectively, in 2020 in comparison to the same in 2019 and this is the major reason for massive reduction in ozone formation (human health) impact in 2020. Combining ozone formation (human health) impact of all fossil fuels together, it shrinks by $\sim 2.04 \mathrm{E}+10$ kg NOx eq globally in 2020 due to COVID-19 situation. Majority of these reduction ( 93.62\%) in ozone formation (human health) occurs due to scaled-down consumption of coal in 2020. Out of the three coals, anthracite carries the highest ozone formation (human health) impact of $\sim 42.5 \%$ of the total, followed by bituminous and lignite coal with approx. $29.3 \%$ and $28.2 \%$ impact, respectively.

\subsubsection{Fine particulate matter formation}

Apart from tropospheric ozone formation, there are other impact contributors that lead to the pollution of atmospheric air. Fine particulate matters with a diameter of less than 2.5 micrometre $(\mu \mathrm{m})$ or $\mathrm{PM} 2.5$ is a significant one in this context. PM2.5 represents a wide variety of organic and inorganic substances including primary and secondary aerosols. Primary PM2.5 includes $\mathrm{NO}_{x}, \mathrm{NH}_{3}, \mathrm{SO}_{2}$ which undergo several reactions in the atmosphere and transform into other secondary aerosols ${ }^{29}$. These particles lead to a wide range of respiratory symptoms followed by various health problems including increasing mortalities ${ }^{22}$. Due to the reduced use of fossil fuels, emission of fine particulate matters will reduce significantly in 2020, as highlighted in Figure 2 (d). On unit process scale, per kg life cycle processes of coal carries $\sim 0.00904 \mathrm{~kg}$ PM2.5 eq impact of fine particulate matter formation which is the maximum value among all fossil fuels under study. Comparatively, 
the life cycle processes of $1 \mathrm{~m}^{3}$ natural gas issue approx. $0.000512 \mathrm{~kg}$ PM2.5 eq which is merely $\sim 5.6 \%$ of what $1 \mathrm{~kg}$ coal entails. In turn, per litre hydrocarbon gas liquid, motor gasoline, residual fuel oil, distillate fuel oil and other oil carry about $0.00372,0.00154$, $0.00187,0.00172,0.00128 \mathrm{~kg}$ PM2.5 eq impact, respectively, over their whole cradle to grave life cycle stages. All total, global fine particulate matter formation impact abates by about 24 million metric ton PM2.5 eq in 2020 due to the reduced consumption of fossil fuels. Majority of this reduction is associated with an impressive change in consumption of three fossil fuels; viz., coal, motor gasoline and distillate fuel oil.

\subsubsection{Smog}

Next, the environmental impacts by mid-point indicator 'smog' show promising results with associated reduction in global smog level in 2020 . About $0.576 \mathrm{~kg}$ ozone $\left(\mathrm{O}_{3}\right)$ eq smog is emitted to the environment based on various life cycle processes of 1 litre hydrocarbon gas liquid which is the highest emission among all fossil fuels. This emission of smog is based on cumulative effect of total 1173 pollutants most of which are issued by nitrogen oxides, volatile organic compounds (VOCs), isoprene, propene and formaldehyde ${ }^{23}$. Nitrogen oxides, VOCs and isoprene also stand as the predominant causes of smog emission in per $\mathrm{kg}$ coal based processes. Other than hydrocarbon gas liquid and coal, per litre life cycle processes of residual fuel oil, distillate fuel oil, gasoline and other oils deliver significant level of smog emission of about $0.0747,0.0686,0.0613$ and $0.0494 \mathrm{~kg} \mathrm{O}_{3} \mathrm{eq}$, respectively. 
$\square 2020 \square 2019$

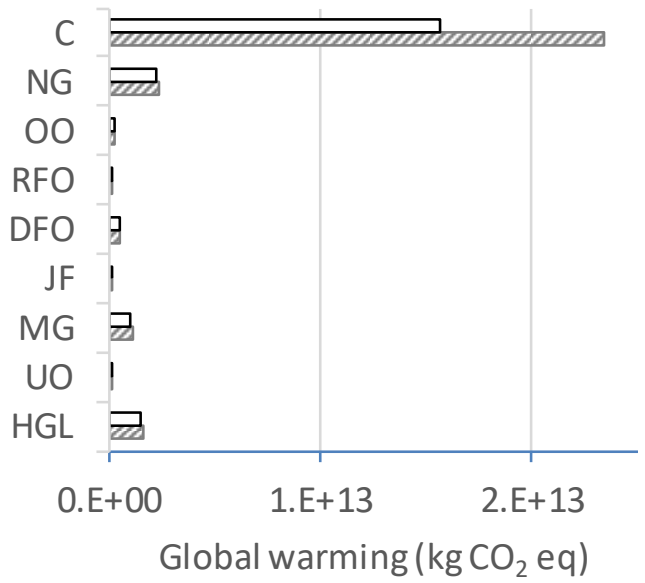

(a)

$\square 2020 \square 2019$

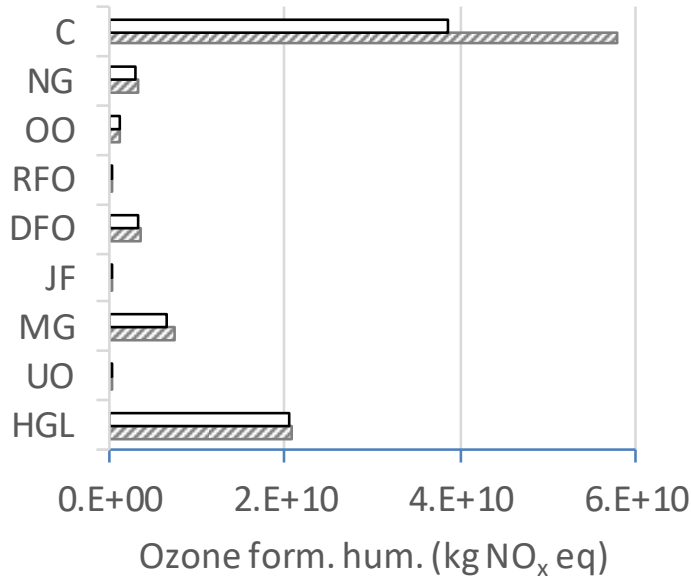

(c) $\square 2020 \square 2019$

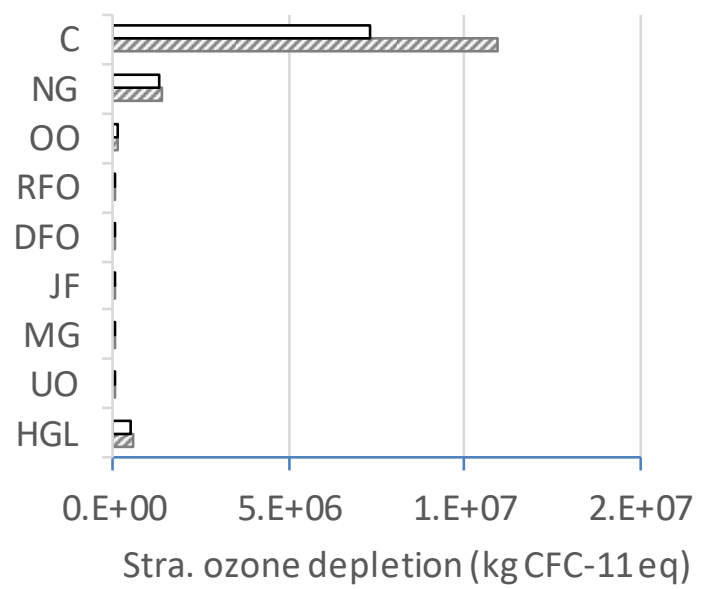

(b)

$\square 2020 \square 2019$

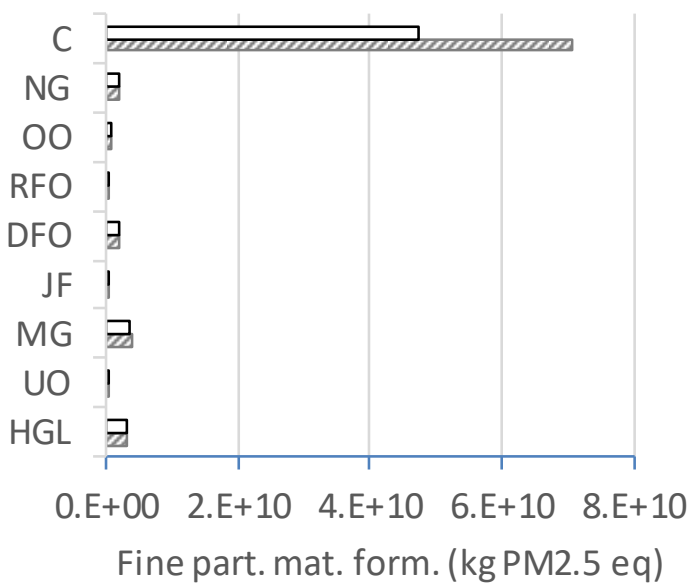

(d) 
$\square 2020$ 『2019

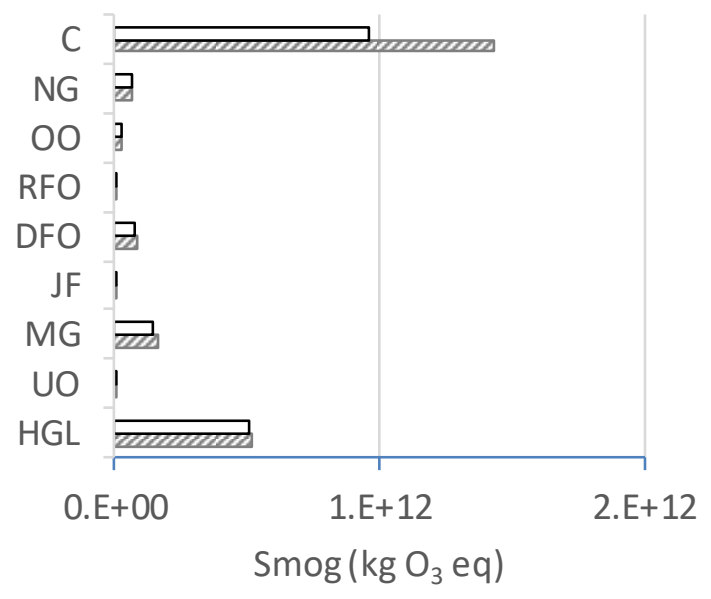

(e)

ㄴ2020 2019

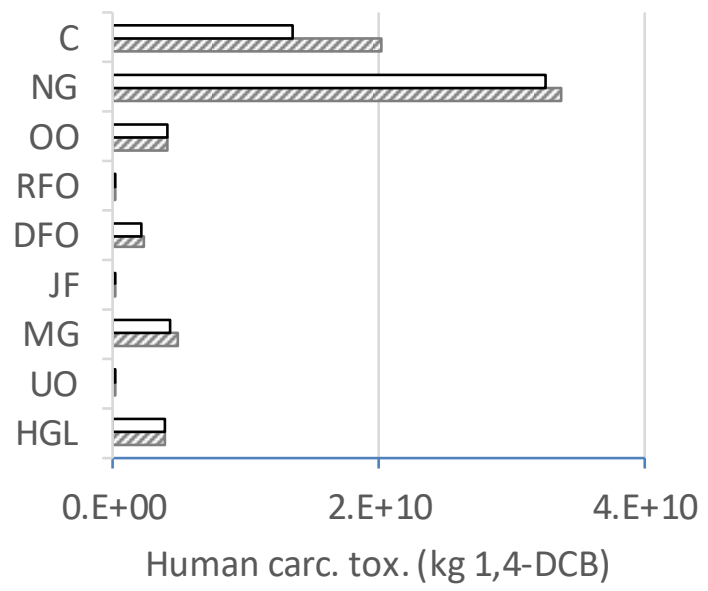

(g)
밈 2019

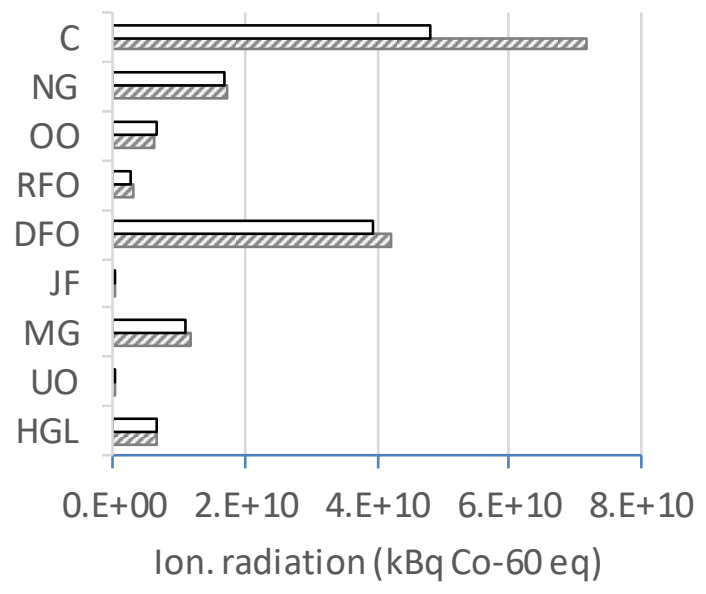

(f)

$\square 2020 \square 2019$

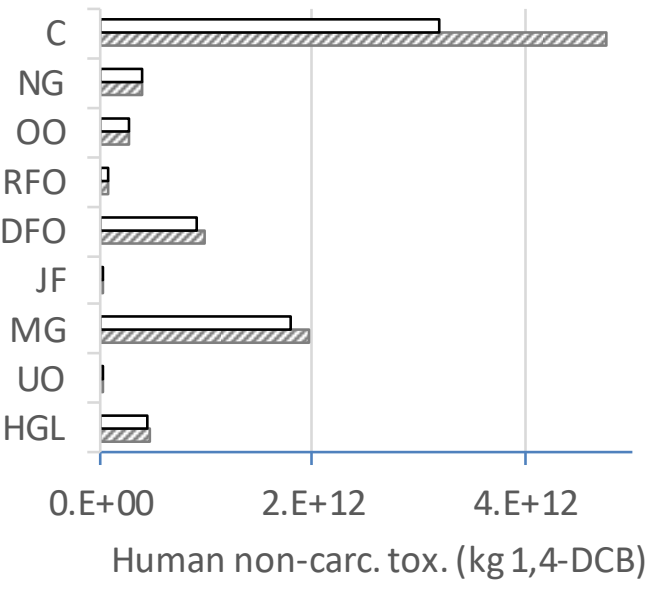

(h) 


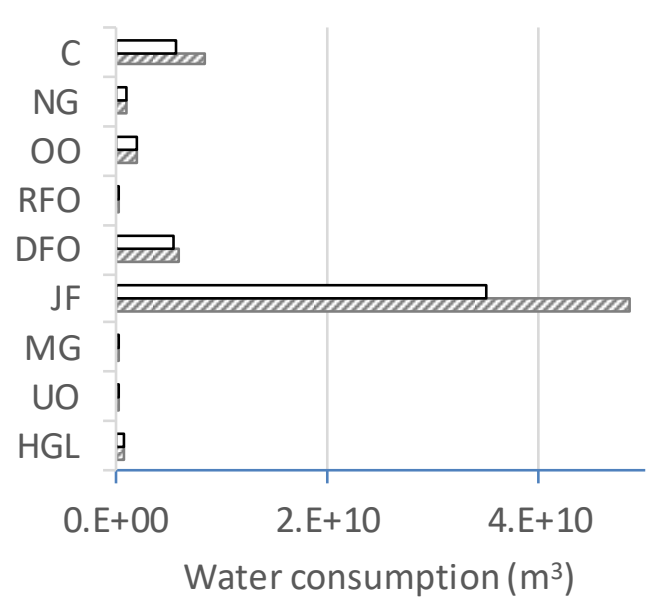

(i)

Figure 2: Change in environmental impacts due to reduced consumption of fossil fuels owing to COVID-19 situation - a) global warming, b) stratospheric ozone depletion, c) ozone formation (human health), d) fine particulate matter formation, e) smog, f) ionizing radiation, g) human carcinogenic toxicity, h) human non-carcinogenic toxicity, and, i) water consumption

\subsection{6 lonizing radiation}

As like most other impacts, there will be a remarkable change in ionizing radiation due to the reduced use of fossil fuels in 2020, as displayed in Figure 2 (f). The ionizing radiation potential of total 63 radionuclides that are released to air, freshwater (rivers and lakes) and marine environment have been studied in this context, for a time horizon of 100 years, to determine the total ionizing radiation of all fossil fuels ${ }^{30}$. Herein, Cobalt-60 (Co-60) stands as the reference substance as like the carbon dioxide equivalence in quantification of global warming impact. Out of all the fossil fuels, the life cycle processes of per litre jet fuel emits the lowest ionizing radiation of about $0.000566516 \mathrm{kBq}$ Co-60 eq where $\mathrm{kBq}$ stands for kilo 
Becquerel (i.e., SI unit of radioactivity). Comparatively, per litre residual fuel oil, distillate fuel oil, unfinished oil, other oil, hydrocarbon gas liquid and motor gasoline carry approx. $64.38,63.48,46.65,20.16,12.79$ and 7.91 times impact of what per litre jet fuel delivers. Other than these, the life cycle processes of per $\mathrm{kg}$ coal and per $\mathrm{m}^{3}$ natural gas exude $\sim 0.0092263$ and $\sim 0.0045 \mathrm{kBq}$ Co-60 eq ionizing radiation impact, respectively. On the basis of total consumption, the topmost contributors in curtailment of ionizing radiation are coal and distillate fuel oil with $\sim 2.37 \mathrm{E}+10$ and $\sim 2.72 \mathrm{E}+09 \mathrm{kBq}$ Co-60 eq impact, respectively. This can be attributed to two factors - i) consumption of these fossil fuels diminishes remarkably in 2020 owing to COVID-19 situation, and, ii) unit process of these fuels carry high ionizing radiation potential.

\subsubsection{Human carcinogenic and non-carcinogenic toxicity}

As like most other environmental impacts, a significant reduction in both human carcinogenic toxicity and human non-carcinogenic toxicity is possible in 2020 due to the diminished use of fossil fuels. The toxicity potentials of all individual chemicals emitted during various life cycle processes of fossil fuels have been quantified for a time horizon of 100 years with reference to the same of $1 \mathrm{~kg}$ 1,4-dichlorobenzene (1,4-DCB). Associated fate, exposure and effect of the toxicities of various chemicals have been based on USESLCA model version $3.0^{31}$. The results from the toxicity modelling show that $1 \mathrm{~m}^{3}$ natural gas carries the highest human carcinogenic toxicity impact of about $0.00882 \mathrm{~kg} 1,4-\mathrm{DCB}$ followed by the life cycle processes of 1 litre other oil, unfinished oil, and hydrocarbon gas liquid with approx. 0.0073, 0.0061 and $0.00435 \mathrm{~kg}$ 1,4-DCB impact, respectively. Similarly, based on the results of non-carcinogenic human toxicity impacts on per litre basis, all the fossil fuels under investigation can be arranged sequentially from higher to lower impacts, 


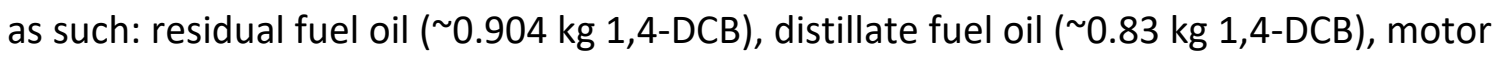
gasoline ( 0.742 kg 1,4-DCB), coal ( $0.61 \mathrm{~kg} 1,4-\mathrm{DCB})$, hydrocarbon gas liquid ( 0.512 kg 1,4DCB), other oils ( $0.487 \mathrm{~kg} 1,4-\mathrm{DCB})$, natural gas ( $0.104 \mathrm{~kg} 1,4-\mathrm{DCB})$, unfinished oil ( 0.0819 kg 1,4-DCB) and jet fuel ( 0.0232 kg 1,4-DCB). The petroleum products are ranked first in this sequence as their base $\mathrm{LCl}$ process, i.e., crude oil production, carries significant noncarcinogenic toxicity impact. In total, about 8.46 million metric ton 1,4-DCB impact will reduce globally in 2020 with respect to the base-case study of 2019 summing up all the reductions in human carcinogenic toxicity impact by all fossil fuels under study. Major contributing fossil fuels in this impact reduction pathways are coal, natural gas and motor gasoline, sequentially, as shown in Figure 2 (g). In comparison to this, global human noncarcinogenic toxicity impact will remarkably reduce by about 1.84 billion metric ton $1,4-\mathrm{DCB}$ based on this LCA study. Coal, motor gasoline and distillate fuel oil will be the leading contributors in these impact reduction pathways, as displayed in Figure 2 (h).

\subsubsection{Water consumption}

Lastly, diminishing consumption of fossil fuels induces an impressive reduction of $\sim 24.8 \%$ in water consumption in 2020. Although a lot of life cycle processes of the fossil fuels necessitate large-scale water resources from various sources, about $90-95 \%$ of this water again returns back to nature by various pathways. Hence, consumptive water just includes $5-10 \%$ of industrial water use across various life cycle processes ${ }^{32}$. Based on this definition, jet fuel and coal deliver an intense reduction in water consumption of about $1.35 \mathrm{E}+10$ and $2.83 \mathrm{E}+09 \mathrm{~m}^{3}$, respectively, in 2020 . Other oil, by contrast, witnesses a $1.51 \%$ rise in consumption and associated rise in all environmental impacts including water consumption, as illustrated in Figure 2 (i). In addition, it appears from per unit based study that per litre 
motor gasoline exhibits the water consumption impact of $\sim 3.38 \mathrm{E}-05 \mathrm{~m}^{3}$. All other fossil fuels issue higher impact than motor gasoline on per unit basis.

\subsection{Results of end-point based environmental impact 'human health'}

At the end-point stage, environmental flows and emissions associated with several midpoint indicators are analytically translated to address separate areas of protection or endpoints. In the present study, all above-mentioned mid-point indicators except smog are aggregated to form the 'human health' end-point impact. 'Disability adjusted life years' or 'DALY' is used here as the reference unit which adds up all 'years of human life lost' and 'years of human life disabled' due to different health and nutrition situation and diseases to the human being through the life cycle processes of fossil fuels ${ }^{7,22}$. Based on the existing definition of 'human health', diminished consumption of fossil fuels across all different sectors of modern civilization cuts down this impact by approx. 23 million DALY in 2020. Details of this impact reduction are illustrated in Figure 3. Using 'world $2010 \mathrm{H} / \mathrm{H}$ normalization and weighting' data set, as available in the ReCiPe end-point method, this 23 million DALY human health impact equals to the same issued by about 6.9 billion people of the world though their daily activities in 2010 (which is the reference year of the normalization results). Out of all the fossil fuels, coal scales down the impact most with a staggering value of $\sim 22.2$ million DALY. All the remaining petroleum based fuels and natural gas contribute to the reduction in 'human health' impact except 'other oils' which increases the 'human health' impact by $\sim 11.3 \mathrm{k}$ DALY as a result of its increasing global consumption in 2020. The above-mentioned analysis, however, excludes the direct effect of COVID-19 which is the primary cause of death of thousands of people in every week in recent months around the world. 


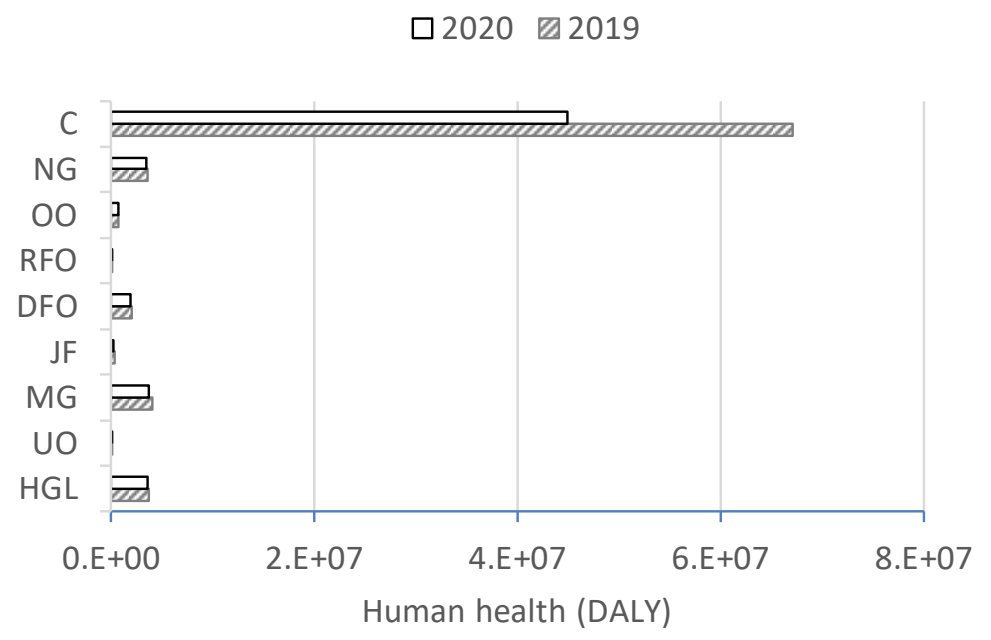

Figure 3: Changes in end-point based environmental impact 'human health' due to reduced consumption of fossil fuels as a result of COVID-19 situation

\subsection{Global GHG emission reduction with respect to IPCC studies}

As discussed in Section 3.1, reduced consumption of fossil fuels decreases the global warming impact immensely in 2020. Combining the contributions of all fossil fuels, the total global warming impact amounts to 29.5 and $\sim 21.5$ billion metric ton $\mathrm{CO}_{2}$ eq in 2019 and 2020 , respectively - this results in total $\sim 8$ billion metric ton $\mathrm{CO}_{2}$ eq GHG emission reduction in 2020. This is a remarkable decrease at a time when the total anthropogenic GHG emission has been in its maximum level since the record started and approximately reached $\sim 59$ billion metric ton $\mathrm{CO}_{2}$ eq per year in 2019 combining the contribution from both fossil and non-fossil sources ${ }^{33,34}$. The GHG emission in 2019 was simultaneously about $13.5 \%$ higher than the GHG emission levels in 2010 (i.e., $52 \pm 5.2$ billion metric ton $\mathrm{CO}_{2}$ eq) which was the reference year of IPCC AR5 $5^{33}$ and was about 55.3\% higher than the emission levels in 1990 (i.e., $38 \pm 3.8$ billion metric ton $\mathrm{CO}_{2}$ eq), the reference year of Kyoto protocol ${ }^{34}$. It is 
noteworthy to mention further that the GHG emission in 1990 is widely used as reference level for 'nationally determined contributions' ${ }^{33}$.

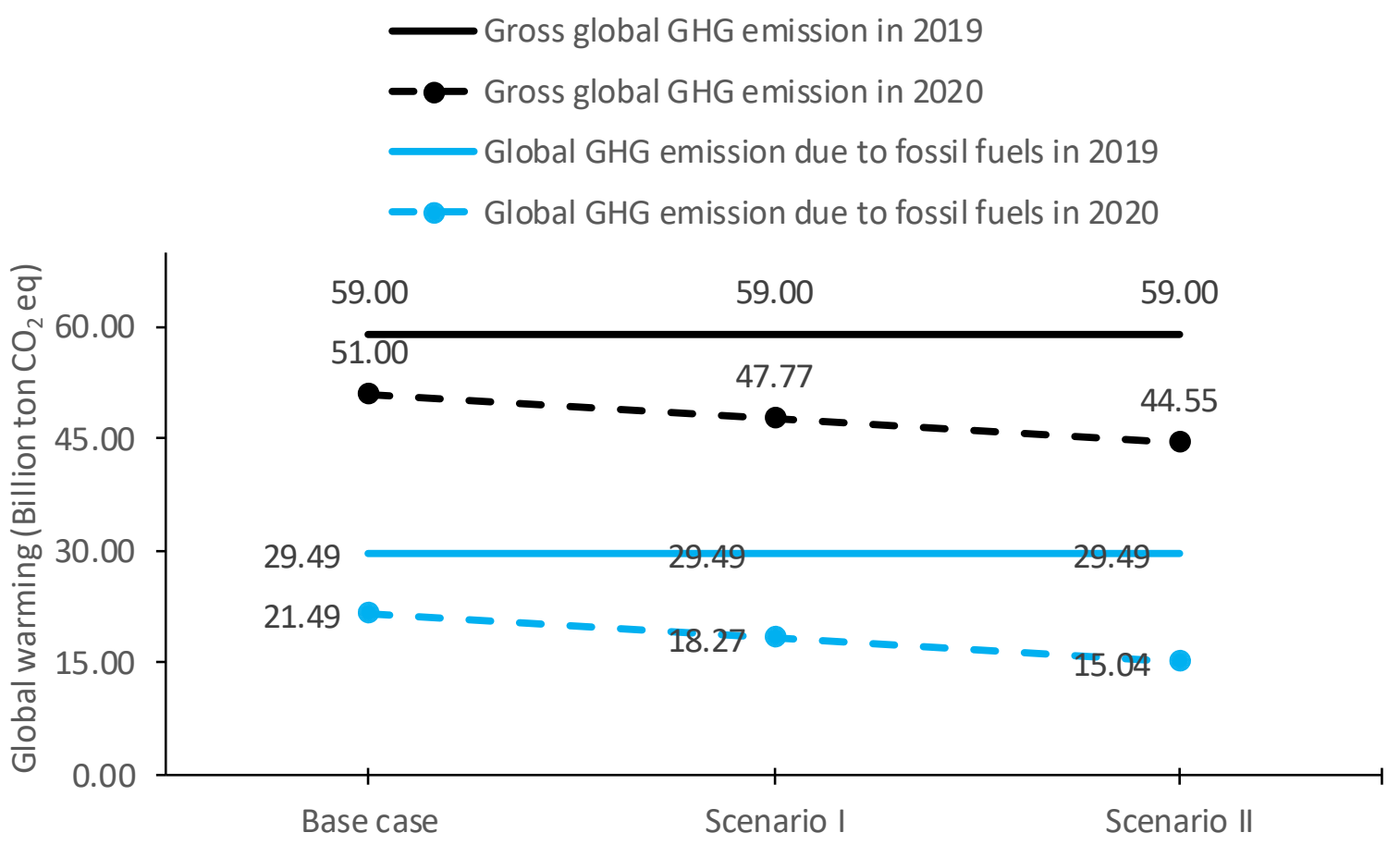

(a) 
Gross global GHG emission in 2019

$\square$ Gross global GHG emission in 2020

Global GHG emission due to fossil fuels in 2019

$\square$ Global GHG emission due to fossil fuels in 2020

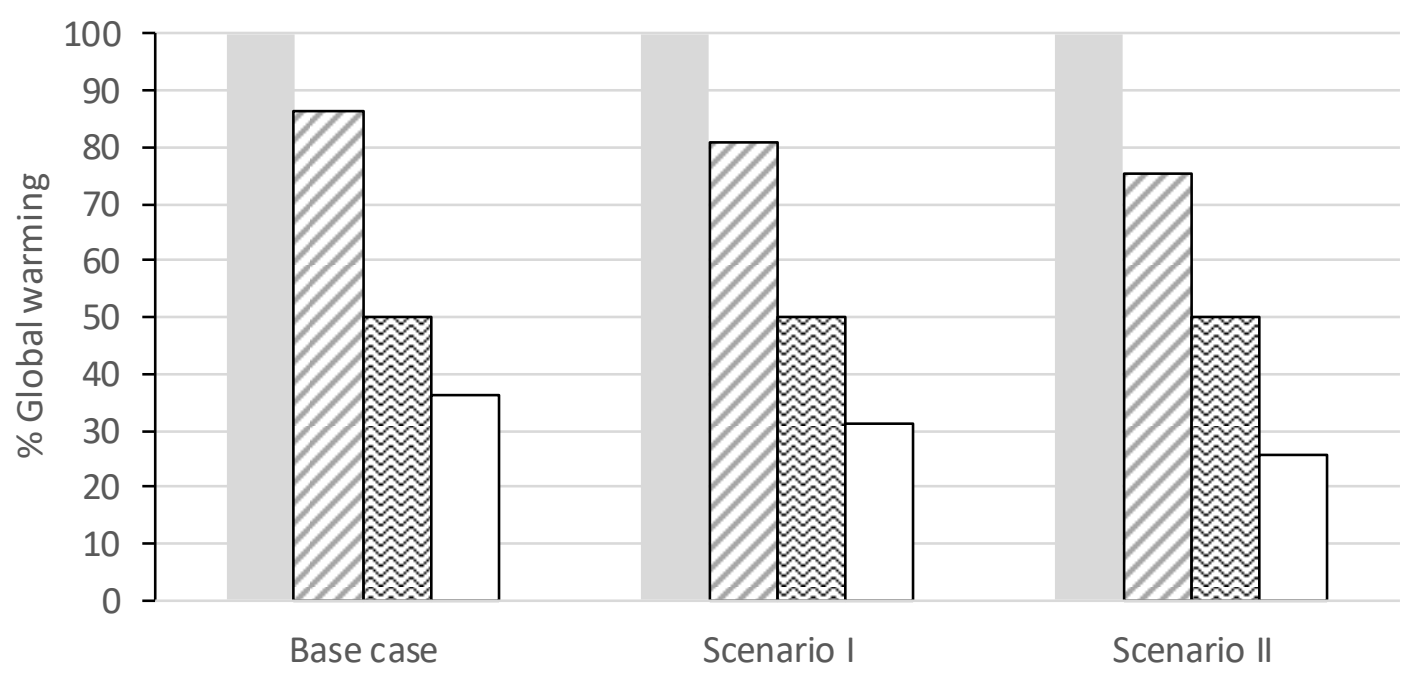

(b)

Figure 4: Changes in worldwide gross GHG emission due to reduced fossil fuel consumption as a result of COVID-19 situation - a) results in billion metric ton $\mathrm{CO}_{2}$ eq; b) results in percentage

Accordingly, the reduction of about 8 billion metric ton $\mathrm{CO}_{2}$ eq or $27.2 \%$ reduction in $\mathrm{GHG}$ emission by fossil fuels scales down the total worldwide GHG emission from fossil and nonfossil sources to $\sim 51$ billion metric ton $\mathrm{CO}_{2}$ eq in 2020 , provided there is no change in GHG emission from non-fossil based sources or activities in this dynamic time. Additionally, this $\sim 51$ billion metric ton $\mathrm{CO}_{2}$ eq GHG emission has not been witnessed by the current human civilization since 2010. This establishes the fact that COVID-19 unveils a significant change in global GHG emission and in associated global warming impact just based on quantifying the GHG reduction by the fossil fuels. 
Figure 4 represents details of the global GHG emission levels both for 2019 and 2020. Herein, the authors highlight three scenarios where the 'base case' scenario represents the GHG emission in 2020, as found in Section 3.1, and 'scenario I' and 'scenario II' model two additional scenarios whereby GHG emission by fossil fuels declines by further $15 \%$ and $30 \%$, respectively, with respect to the 'base case' scenario. These 'scenario I' and 'scenario II' basically refer to the situation where COVID-19 pandemic further batters the world economy and reduces the anthropogenic activities globally. Accordingly, 'base case', 'scenario I' and 'scenario II' reduce the contribution of GHG emission by fossil fuels by approx. $27.14 \%, 38.06 \%$ and $48.99 \%$, respectively, in 2020 . Same GHG emissions, as in 'base case', 'scenario I' and 'scenario II' cases, ensure about $13.56 \%, 19.03 \%$ and $24.49 \%$ reduction in 2020 with respect to the total worldwide anthropogenic GHG emissions in 2019, as shown in Figure 4 (b). This is undoubtedly a remarkable change in GHG emission worldwide due to COVID-19 situation. However, this is not beyond expectation based on the fact that fossil fuels consistently carry a dominant share in total worldwide anthropogenic GHG emissions. For instance, these fuels contributed about $61.54 \%$ of total worldwide anthropogenic GHG emission in $2010^{33,34}$.

\section{Conclusion}

The study has conducted an evidence-based analysis of how COVID-19 initiated a drastic change in global environment at a particular time when the world has been grappling with series of compelling environmental issues. The dreadful coronavirus 2 (SARS-CoV-2) has threatened the current human civilization in one hand whereas the environmental restoration process is continuing on the other hand. In future, unfolding time, or once the pandemic ends, human being will be further able to decide whether some sort of partial 
lockdown or social restriction on a rolling basis in different corners of the world could play a key role in balancing the global ecosystem and environment. But as of now, this study carries testimonies of meaningful transitions in global environment in 2020 due to COVID19, as such:

- global warming impact reduces by $\sim 27.14 \%$ with respect to the 2019 level with a corresponding reduction of $\sim 8.0$ billion metric ton $\mathrm{CO}_{2}$ eq;

- stratospheric ozone depletion impact reduces by $28.14 \%$ with respect to the 2019 level with a corresponding reduction of $\sim 3.68 \mathrm{E}+06 \mathrm{~kg}$ CFC11 eq;

- ozone formation human health reduces by $21.71 \%$ with respect to the 2019 level with a corresponding reduction of $\sim 2.04 \mathrm{E}+10 \mathrm{~kg} \mathrm{NO}$ eq;

- fine particulate matter formation reduces by $\sim 28.86 \%$ with respect to the 2019 level with a corresponding reduction of $\sim 2.4 \mathrm{E}+10 \mathrm{~kg} P \mathrm{PM} 2.5$ eq;

- smog reduces by $22.04 \%$ with respect to the 2019 level with a corresponding reduction of $\sim 5.06 \mathrm{E}+11 \mathrm{~kg} \mathrm{O} 3$ eq;

- ionizing radiation reduces by $\sim 17.89 \%$ with respect to the 2019 level with a corresponding reduction of $\sim 2.85 \mathrm{E}+10 \mathrm{kBq}$ Co-60 eq;

- human carcinogenic toxicity reduces by $\sim 12.21 \%$ with respect to the 2019 level with a corresponding reduction of $\sim 8.46 \mathrm{E}+09 \mathrm{~kg} 1,4-\mathrm{DCB}$;

- human non-carcinogenic toxicity reduces by $\sim 20.62 \%$ with respect to the 2019 level with a corresponding reduction of $\sim 1.84 \mathrm{E}+12 \mathrm{~kg} 1,4-\mathrm{DCB}$;

- water consumption reduces by $\sim 24.80 \%$ with respect to the 2019 level with a corresponding reduction of $\sim 1.68 \mathrm{E}+10 \mathrm{~m}^{3}$. 
Finally, we recommend conducting more LCA studies for investigating other environmental impacts and ecosystem changes, materializing due to COVID-19, by exploiting other LCA methods.

\section{CRediT authorship contribution statement:}

A. Rashedi: Conceptualization, Methodology, Investigation, Software, Data curation, Visualization, Formal analysis, Roles/Writing - original draft, Writing - review \& editing. Taslima Khanam: Investigation, Formal analysis, Visualization, Writing - review \& editing. R. Saidur: Investigation, Formal analysis, Validation, Writing - review \& editing.

\section{Acknowledgements}

This research did not receive any specific grant from funding agencies in the public, commercial, or not-for-profit sectors.

\section{Declaration of Competing Interest}

The authors declare no competing interests.

\section{Appendix A. Supplementary Materials}

Separate Supplementary Materials have been provided.

\section{References}

1. Wang, Q., Su, M. A preliminary assessment of the impact of COVID-19 on environment - A case study of China. Sci. Total Environ. 728138915.

https://doi.org/10.1016/j.scitotenv.2020.138915 (2020). 
2. Le Quéré, Q. et al. Temporary reduction in daily global CO2 emissions during the COVID19 forced confinement. Nat. Clim. Chang. https://doi.org/10.1038/s41558-020-0797-x (2020).

3. Abdullah, S. et al. Air quality status during 2020 Malaysia Movement Control Order (MCO) due to 2019 novel coronavirus (2019-nCoV) pandemic. Sci. Total Environ. 729139022. https://doi.org/10.1016/j.scitotenv.2020.139022 (2020).

4. Yunus, A. P., Masago, Y. \& Hijioka, Y. COVID-19 and surface water quality: Improved lake water quality during the lockdown. Sci. Total Environ. 731139012. https://doi.org/10.1016/j.scitotenv.2020.139012 (2020). 5. La Rosa, G., Bonadonna, L., Lucentini, L., Kenmoe, S. \& Suffredini, E. Coronavirus in water environments: Occurrence, persistence and concentration methods - A scoping review. Wat. Res. 179, 115899. https://doi.org/10.1016/j.watres.2020.115899 (2020). 6. Saadat, S., Rawtani, D. \& Hussain, C. M. Environmental perspective of COVID-19. Sci. Total Environ. 728 138870. https://doi.org/10.1016/j.scitotenv.2020.138870 (2020).

7. Rashedi, A., Khanam, T. Life cycle assessment of most widely adopted solar photovoltaic energy technologies by mid-point and end-point indicators of ReCiPe method. Environ. Sci. Pollut. Res. https://doi.org/10.1007/s11356-020-09194-1 (2020). 8. Rashedi, A. Sridhar, I. \& Tseng, K. J. Life cycle assessment of $50 \mathrm{MW}$ wind firms and strategies for impact reduction. Renew. Sust. Ene. Rev. 21, 89-101 (2013).

9. Rashedi, A. Sridhar, I., Tseng, K. J. \& Srikanth, N. Minimum mass design of thin tubular structures under eccentric compressive loading. Thin-Walled Struct. 90, 191-201 (2015). 10. Goedkoop, M. et al. ReCiPe 2008 Report I: characterisation (v 1.08), Amsterdam, The Netherlands. 
11. Hauschild, M. Z. et al. Identifying best existing practice for characterization modeling in life cycle impact assessment. Int. J. Life Cycle Assess. 18, 683-697 (2013).

12. US Energy Information Administration. Monthly Energy Review April 2020. DOE/EIA0035(2020/4). Office of Energy Statistics, U.S. Department of Energy, Washington, USA (2020).

13. US Energy Information Administration. Short-Term Energy Outlook June 2020.

Office of Energy Statistics, U.S. Department of Energy, Washington, USA (2020).

14. US Energy Information Administration. Short-Term Energy Outlook August 2020.

Office of Energy Statistics, U.S. Department of Energy, Washington, USA (2020).

15. David, J., Murphy, C., Hall, A. S. Adjusting the economy to the new energy realities of the second half of the age of oil. Eco. Model. 223, 67-71 (2011).

16. Campbell, C. J. The Rimini Protocol an oil depletion protocol: Heading off economic chaos and political conflict during the second half of the age of oil. Ene. Pol. 34, 1319-1325 (2006).

17. ISO (2006a) International Standard Organization. Environmental management

- Life cycle assessment - principles and framework. Reference number ISO 14040:2006(E), Geneva, Switzerland (2006).

18. ISO (2006b) International Standard Organization. Environmental management

- life cycle assessment - requirements and guidelines. Reference number ISO 14044:2006(E), Geneva, Switzerland (2006).

19. U.S. Life Cycle Inventory Database." National Renewable Energy Laboratory, 2012. Accessed in Jun, 2020 (2012). 
20. The European Reference Life Cycle Database. Joint Research Centre, Institute for Environment and Sustainability (JRC-IES), European Platform on Life Cycle Assessment (2020).

21. Ecoinvent version 3.5. As available in https://www.ecoinvent.org/database. Accessed in Jun, 2020 (2018).

22. ReCiPe 2016 v1.1. A harmonized life cycle impact assessment method at midpoint and endpoint level. Report I: Characterization. RIVM Report 2016-0104a. National Institute for Public Health and the Environment, Bilthoven, The Netherlands (2017).

23. Tool for Reduction and Assessment of Chemicals and Other Environmental Impacts (TRACI). EPA/600/R-12/554. National Risk Management Research Laboratory, U.S.

Environmental Protection Agency, Cincinnati, USA (2012).

24. SimaPro version 9.0.0.41. PRé. Quantifying sustainability. As available in https://www.presustainability.com/. Accessed in Jun, 2020 (2019).

25. Stocker, T. F. et al. IPCC 2013. The Physical Science Basis. Contribution of Working Group I to the Fifth Assessment Report of the Intergovernmental Panel on Climate Change. Cambridge University Press, Cambridge, United Kingdom and New York, NY, USA, 1535 pp, doi:10.1017/CBO9781107415324 (2013).

26. Urban, M. C. Accelerating extinction risk from climate change. Science 348, 571-573 (2015).

27. World Meteorological Organization. Scientific assessment of ozone depletion: 2010, Global Ozone Research and Monitoring. Project-report no. 52, Geneva, Switzerland (2011). 28. Hayashi, K., Nakagawa, A., Itsubo, N., \& Inaba, A. Expanded Damage Function of Stratospheric Ozone Depletion to Cover Major Endpoints Regarding Life Cycle Impact Assessment. Int. J. Life Cycle Assess. 11, 150-161 (2006). 
29. World Health Organization. Health risks of air pollution in Europe-HRAPIE project recommendations for concentration-response functions for cost benefit analysis of particulate matter, ozone and nitrogen dioxide, Geneva, Switzerland (2013).

30. Frischknecht, R., Braunschweig, A., Hofstetter, P. \& Suter, P. Human health damages due to ionising radiation in life cycle impact assessment. Environ. Imp. Assess. Rev. 20, 159-189 (2000).

31. Van Zelm, R., Stam, G., Huijbregts, M. \& Van de Meent, D. Making fate and exposure models for freshwater ecotoxicity in life cycle assessment suitable for organic acids and bases. Chemos. 90 (2), 312-317 (2013).

32. Pfister, S., Koehler, A., and Hellweg, S. Assessing the Environmental Impacts of Freshwater Consumption in LCA. Environ. Sci. Tech. 43 (11), 4098-4104 (2009).

33. Edenhofer, O. et al. IPCC 2014. Mitigation of Climate Change. Contribution of Working Group III to the Fifth Assessment Report of the Intergovernmental Panel on Climate Change Cambridge University Press, Cambridge, UK, and New York, NY, USA (2014).

34. Masson-Delmotte, V. et al. IPCC 2018. Summary for Policymakers. In: Global Warming of $1.5^{\circ} \mathrm{C}$. An IPCC Special Report on the impacts of global warming of $1.5^{\circ} \mathrm{C}$ above pre-industrial levels and related global greenhouse gas emission pathways, in the context of strengthening the global response to the threat of climate change, sustainable development, and efforts to eradicate poverty (2018). 